\title{
Hands Free, Automated Transmission Electron Microscopy (TEM) Wedge Sample Preparation.
}

\author{
Efrat Raz-Moyal, * and Drew Erwin* \\ * Gatan Inc., 5794 W. Las Positas Blvd. Pleasanton, CA 94588
}

Transmission Electron Microscopy (TEM) Sample Preparation (SP) has developed greatly in the recent years, mainly in the area of Focus Ion Beam (FIB). The FIB became the ultimate solution for site specific TEM SP, as the specimen can be imaged for exact placement of the final milling window (DualBeam ${ }^{\mathrm{TM}}$ instrument). While the FIB offers great advantages, re precision, ease of use and mostly independent from the nature of the sample material, it is costly (both on capital investment and cost of operation - COO), the thinned area is small (microns), surface amorphization is visible in semiconductor materials, and possibly form Ga intermetallic compounds.

One of the preferred alternative method to FIB for non site specific SP and to overcome the FIB disadvantages is mechanical polishing of a wedge sample to transparency with final broad Ar ion beam milling. This method can process both plan view and cross section view specimens, producing large thin area and reduce broad ion milling times to minutes. This method is low on costs, offer a solution for large area investigation and for Ga sensitive material.

The biggest drawback for this method is its absolute reliance on technician experience and expertise and of course, natural human limitations. The control over polishing parameters, such as time, angle, force is coarse. The ability to incrementally, on going fine-adjust the parameters, while transferring between polisher and microscope is limited. Therefore, the success and repeatability rate are hard to predict, while the process is long and cumbersome.

This paper will describe a hands-free, automated wedge TEM SP technique, which offers all the advantages of mechanical polishing of a wedge sample, while eliminating the disadvantages described in the previous paragraph. The sample is processed by a computer control polishing system with an in situ microscope, CCD, advance image processing and 3D angle control. The system integrates the polishing, the imaging, the on going fine-adjustments of the polishing parameters and the closed loop end point steps hands-free. Consequently, successful results are obtained by any user after a short training cycle. Fine control over the polishing parameters allows increased precision, larger thinned area $(1 \mathrm{~mm})$, high success rate and repeatability at high throughput. This technique can also be used to prepare a thin, $<2-3$ um specimen for FIB, which will reduce FIB milling time and a reduced fluorescence yield contribution from the neighboring material in analytical TEM investigations with energy-dispersive x-ray analysis (EDX).

Experiments are in progress to use this technique to prepare a thin specimen that is TEM ready and eliminate ion mill step all together, FIB or broad beam. 
The following describes the key process flow steps:

\begin{tabular}{|l|l|}
\hline $\begin{array}{l}\text { Side 1: } \\
\text { Select TEM side-1 option. } \\
\text { The sample is } \\
\text { automatically cross } \\
\text { sectioned at zero degrees to } \\
\text { the pre-selected target. The } \\
\begin{array}{l}\text { PolishEye and image- } \\
\text { processing close the loop } \\
\text { with that end point. }\end{array}\end{array}$ \\
$\begin{array}{l}\text { Side 2A: } \\
\text { Select "TEM side 2" option } \\
\text { and define 5-um, as the } \\
\text { final desired thickness } \\
\text { (with 1-deg angle). The } \\
\text { edge-to-edge algorithm } \\
\text { will continuously measure } \\
\text { the thickness (top view) } \\
\text { and end the process once } \\
\text { the desired thickness has } \\
\text { been reached. }\end{array}$ \\
$\begin{array}{l}\text { Sample on a stub- using hot wax } \\
\text { Side 2B: }\end{array}$ \\
$\begin{array}{l}\text { 5-um down to 1-um in } \\
\text { thickness using in-situ } \\
\text { incremental polish \& } \\
\text { stitched view until end } \\
\text { point is reached. }\end{array}$
\end{tabular}

\section{References:}

[1] Joachim Mayer, Lucille A. Giannuzzi, Takeo Kamino, and Joseph Michael, MRS BULLETIN • VOLUME 32 - MAY 2007.

[2] J.D. Casey et al., J. Vac. Sci. Technol. B 20, 2682 (2002).

[3] J.R. Michael, Microsc. Microanal. 12 suppl. 2, 1248CD (2006).

[4] R. Spolenak, L. Sauter, C. Eberl, Scripta Mater. 53, 1292 (2005).

[5] R.M. Langford, D. Ozkaya, B. Huey, A.K. Petford-Long, Proc. Royal Microsc. Soc.: Microscopy of Semiconducting Materials XII (2001) pp. 511-514.

[6] Z. Huang, J. Microsc. 215, 219 (2004).

[7] N.I. Kato, J. Electron Microsc. 53, 451 (2004). 